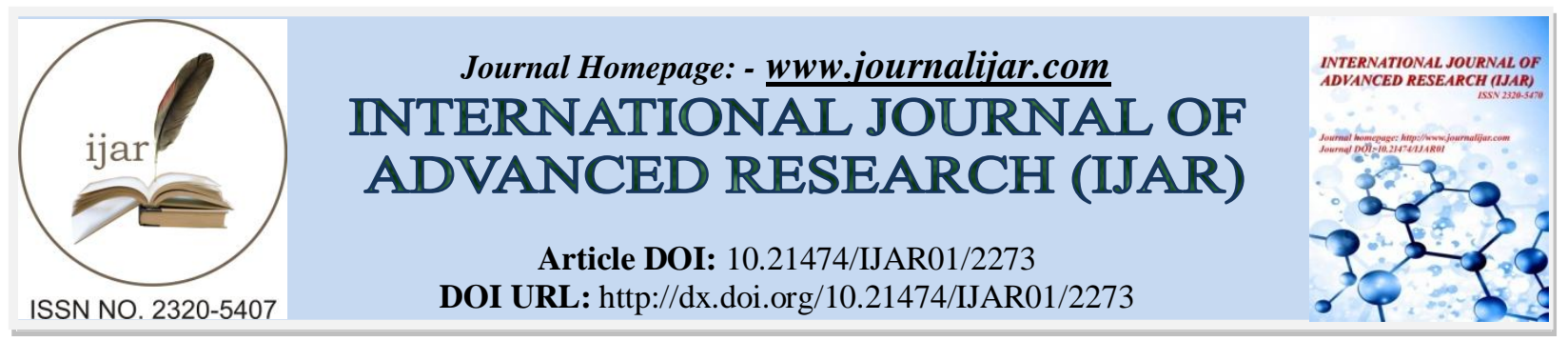

RESEARCH ARTICLE

\title{
ROLE OF APOE-84 ALLELE IN RECOVERY FROM TRAUMATIC BRAIN INJURY: STUDY IN A TERTIARY CLINIC IN KOLKATA.
}

\section{Nikhil Talathi ${ }^{1}$, Sarani Nath ${ }^{2}$, Sarnava Roy ${ }^{2}$, Anindita Joardar*², Shubhamitra Chaudhuri ${ }^{1}$, Goutam \\ Gangopadhyay ${ }^{3}$ and Samarendra Nath Ghosh ${ }^{1}$.}

1. Department of Neurosurgery, Bangur Institute of Neurosciences, Kolkata.

2. Neurogenetic Unit, Department of Neurology, Bangur Institute of Neurosciences, Kolkata.

3. Department of Neurology, Bangur Institute of Neurosciences Kolkata.

\section{Manuscript Info}

(...........................

Manuscript History

Received: 29 September 2016

Final Accepted: 30 October 2016

Published: November 2016

Key words:-

Apolipoprotein E; traumatic brain injury;

Glassgow Outcome Scale, PCR, RFLP.

\section{Abstract}

The outcome of traumatic brain injury is quite variable and not fully explained by known factors. There are conflicting reports regarding the association between the ApolipoproteinE- $\varepsilon 4$ allele and the consequence of traumatic brain injury (TBI). Our objective was to examine if the polymorphism of ApolipoproteinE has any influence on the outcome of TBI. A TOTAL OF 172 patients who suffered from mild or moderate head injury and who are admitted to the hospital emergency ward within $24 \mathrm{~h}$ of traumatic brain injury or underwent emergency surgery for head injury were enrolled in the study. With previous informed consent $5 \mathrm{ml}$ venous blood samples were collected from patients \& preserved in EDTA at $-20^{\circ} \mathrm{C}$. PCR and RFLP techniques were used to find out the allele of Apo E. All discharged patients were followed up after 6 months and allocated to one of the categories of Glasgow Outcome Scale by means of structured interview. Any significant association between ApoE- $\varepsilon 4$ and traumatic brain injury in the patients from this part of India could not be ascertained and this is comparable to most of the other studies conducted in other parts of India and the world.

Copy Right, IJAR, 2016,. All rights reserved.

\section{Introduction:-}

A patient with TBI is a person who has had a traumatically induced physiological disruption of brain function, which is manifested by at least one of the following:

1. Any period of loss of consciousness,

2. Any loss of memory for events immediately before or after the accident,

3. Any alteration in mental state at the time of the accident (e.g. feeling dazed, disoriented, or confused), or

4. Focal neurological deficit(s) which may or may not be transient ${ }^{1}$.

This definition of TBI includes the head being struck, the head striking an object, or the brain undergoing an acceleration/deceleration movement (i.e. whiplash) without direct external trauma to the head. Different approaches to classification of TBI exist. From a mechanistic perspective, closed, penetrating, crush, and blast injuries are

Corresponding Author:- Anindita Joardar.

Address:- Neurogenetic Unit, Department of Neurology, Bangur Institute of Neurosciences, Kolkata. 
distinguished. Blast injuries have recently been identified as a separate entity and are frequently caused by improvised explosive devices used during armed conflicts and terrorist activities.

The clinical severity of intracranial injuries is commonly assessed according to the degree of depression of the level of consciousness as assessed by the Glasgow Coma Scale (GCS) ${ }^{2}$. The GCS consists of the sum score (range, 3 to 15) of three components (eye, motor, and verbal scales), each assessing different aspects of reactivity. The motor component provides more discrimination in patients with severe injuries, whereas the eye and verbal scales are more discriminative in patients with moderate and mild injuries ${ }^{3}$. For assessment of severity in individual patients, the three components should be reported separately. For purposes of classification, however, calculation of the sum score is useful. Severe TBI is defined as a GCS score of 3 to 8, moderate TBI as a GCS score of 9 to 13, and mild TBI as a GCS score of 14 to $15^{3}$ as described in table 1 .

Apolipoprotein E- $\varepsilon 4$ (ApoE- $\varepsilon 4)$ is one such factor whose presence has been associated with increased incidence and faster progression of neurodegenerative disease, poorer recovery from neurologic insults and decreased cognitive function in the well-elderly. The specific association between Apo E genotype and recovery from severe traumatic brain injury (TBI) is conflicting with many groups finding the ApoE- $\varepsilon 4$ allele to be associated with poorer outcome while others have found no association.

Apolipoprotein E (ApoE) is a class of Apolipoprotein found in the chylomicron and Intermediate-density lipoprotein (IDLs) that is essential for the normal catabolism of triglyceride-rich lipoprotein constituents. ${ }^{4}$ ApoE is 299 amino acids long and transports lipoproteins, fat-soluble vitamins, and cholesterol into the system and then into the blood ${ }^{5}$. It is synthesized principally in the liver, but has also been found in other tissues such as the brain, kidneys, and spleen. It is synthesized principally in the liver and macrophage but has also been found in other tissues such as the brain, kidneys, and spleen. In the nervous system, non-neuronal cell types, most notably astroglia and microglia, are the primary producers of ApoE, while neurons preferentially express the receptors for ApoE. It mediates cholesterol metabolism in an isoform-dependent manner. In the central nervous system, ApoE is mainly produced by astrocytes, and transports cholesterol to neurons via ApoE receptors, which are members of the family. It also transport lipoproteins, fat-soluble vitamins, and cholesterol into the lymph system and then into the blood.

The gene, ApoE, is mapped to chromosome 19 in a cluster with Apolipoprotein $\mathrm{C} 1$ and the Apolipoprotein $\mathrm{C} 2$. The ApoE gene consists of four exons and three introns, totaling 3597 base pairs. ApoE is transcriptionally activated by the liver X receptor (an important regulator of cholesterol, fatty acid, and glucose homeostasis) and peroxisome proliferators-activated receptor $\gamma$, nuclear receptors that form heterodimers with Retinoid $\mathrm{X}$ receptors ${ }^{6}$. ApoE is polymorphic ${ }^{7,8}$ with three major alleles: ApoE- 22 (cys112, cys158), ApoE- 83 (cys112, arg158), and ApoE$\varepsilon 4(\arg 112, \arg 158)^{9}$. Although these allelic forms differ from each other by only one or two amino acids at positions 112 and $158^{10,11,12}$, these differences alter ApoE structure and function.

\section{Materials and Methods:-}

The present study was conducted in the department of Neurosurgery, Institute of Post- Graduate Medical Education and Research \& Bangur Institute of Neuroscience, Kolkata for a period of 2 years from February 2014 to February 2016 after getting clearance from the Institutional Ethics Committee. Consecutive traumatic brain injury patients, both mild and moderate in severity, in whom the presence of ApoE isoform had been established by molecular biological methods and who are admitted to the hospital emergency ward within $24 \mathrm{hr}$. of onset of the traumatic brain injury or underwent emergency surgery for head injury were enrolled in the study. The age of those enrolled patient was more than 15 years. Critically ill patients with severe head injury and having associated chest, abdomen and spine or limb injuries were excluded from the study. After the exclusion criteria had been assessed in each patient, informed consent was taken from the patients themselves or their legal guardians (in the case of unconscious patient). Only those who gave consent were enrolled in the study.

With previous informed consent $5 \mathrm{ml}$ venous blood sample collected from patient and preserved in EDTA at $-20^{\circ} \mathrm{C}$ for detection of ApoE genotype. DNA was isolated from leukocytes by standard phenol- chloroform method. From this separated DNA, ApoE gene was amplified by polymerase chain reaction (PCR) using100 ng of the genomic DNA with specific primers mentioned in the table 2 
These amplified gene products were subjected to restriction fragment length polymerization (RFLP) using restriction enzyme Hha 1 (promega). The digested product was further separated on 4\% agarose gel and visualized under UV light by gel documentation system.

\section{Treatment Protocol \& Follow-Up:-}

Patients of head injury were admitted in emergency ward and after evaluation started on standard treatment protocol as per clinical and Neuroimaging findings. If necessary they underwent emergency surgery for head injury. All discharged patients were followed up at 6 months and allocated to one of the categories of Glasgow outcome scale by means of structured interview.

\section{Baseline assessments:-}

The age, sex, contact information, educational status, occupation ,marital status, date and time of admission recorded and information was collected on the following variables: mode of injury, date and time of injury, route of referral, initial examination including GCS, Neuroimaging data, operative notes if any surgical procedure is done, GCS at the time of discharge.

\section{Assessment of Outcome:-}

The primary outcome this study was the 'functional outcome' determined by the Glasgow outcome Score at the end of the $6^{\text {th }}$ month after discharge. For the primary assessment the patients with various Apo E genotypes were grouped into ApoE- $\varepsilon 4$ positive (including patients with one or two $\varepsilon 4$ alleles) and ApoE- $\varepsilon 4$ negative (patients without $\varepsilon 4$ alleles). Statistical analysis was done to determine if there were significance between the two groups in the distribution of patients by chi square test and fisher exact test when needed. The level of significance was $p<0.05$ in all analysis. For data management and statistical calculations, SPSS software was used.

\section{Results:-}

We had recruited total 172 patients in our study. ApoE genotyping was done in 172 (total population) patients. Complete hospital data and a minimum 6 months' follow up data is available for 133 patients.

Patients with single or both $\varepsilon 4$ alleles were considered to be ApoE- $\varepsilon 4$ positive. In our study $\varepsilon 3 / \varepsilon 3$ allele was the most commonly found allele $(79.1 \%$ ) whereas single or both ApoE- $\varepsilon 4$ alleles was present in $6.5 \%$ of the samples and $\varepsilon 2 / \varepsilon 3$ was present in $14.5 \%$ of the samples. $\varepsilon 4 / \varepsilon 4$ allele was present only in two out of 172 patients $(1.2 \%)$. None of the patient had $\varepsilon 2 / \varepsilon 2$ alleles. The distribution of ApoE gene is shown in table 3 .

We divided age groups of patients as 20 years and less (young), 21-40 years and 41-60 (working population), more than 60 years (old). The mean age of our study population was 36.34 years for ApoE- $\varepsilon 4$ negative and 42.45 years for ApoE- $\varepsilon 4$ positive patients. From table 4, it is evident that head injury is most common in 21-40 years age group (i.e. $50 \%$ ) followed by $41-60$ years age group $(28.5 \%)$.

As only 133 patient turned up for follow up within 6 months, this group is further divided with respect to type of head injury as either mild (GCS- 13 to 15 ) or moderate (9 to 12) which is classified at the time of admission. From table 5, it is evident that patients initial GCS after the head injury are equally distributed in all age groups irrespective of their ApoE- $\varepsilon 4$ status.

Road traffic accident (RTA) is the most common cause of Head Injury in our study (73.3\%). Fall from height is the next common cause (18.6\%). Other causes (8.1\%) include assault (7), fall of some object on head (3), hit by cricket ball (1) \& trauma due to bore-well rod (3) (Table 6). Forty four out of $126(34.9 \%)$ RTA patients were under the influence of alcohol at the time of Head Injury. If we consider drink and drive; total 38 out of 61 (62\%) drivers were under alcohol influence.

Among 133 patients who came for follow up, 17 out of 122 ApoE- $\varepsilon 4$ negative patients had poor outcome whereas only 2 out of 11 ApoE- $\varepsilon 4$ positive patients showed poor outcome as shown in table 7. Considering GOS of 1-3 as unfavorable and 4-5 as favorable as done by Teasdale et.al. ${ }^{13}$, the difference between two groups is not significant. $(p=0.699$ at degree of freedom 1$)$

After a six month follow up, 77 of the 122 ApoE- 84 negative patients showed complete recovery with GOS of 5 whereas only 2 out of 11 Apo-E4 positive patients had GOS of 5 after six months of follow up. The favorable 
outcome seems to be incomplete in ApoE- $\varepsilon 4$ positive group. These patients are otherwise normal but suffering from mild headaches, lack of concentration, and dizziness significantly more as compared to ApoE- $\varepsilon 4$ negative group.

Table 1:- Glasgow Coma Scale.

\begin{tabular}{|c|c|c|}
\hline Best Eye Response (4) & Best Verbal Response (5) & Best Motor Response (6) \\
\hline 1. No eye opening & 1. No verbal response & 1. No motor response \\
\hline 2. Eye opening to pain & 2. Incomprehensible sounds & 2. Extension to pain \\
\hline 3. Eye opening to verbal command & 3. Inappropriate words & 3. Flexion to pain \\
\hline 4. Eyes open spontaneously & 4. Confused & 4. Withdrawal from pain \\
\hline & 5. Oriented & 5. Localizing pain \\
\hline & & 6. Obeys Commands \\
\hline
\end{tabular}

Table 2:- Primer sequence for PCR of Apolipoprotein gene

\begin{tabular}{|c|c|c|}
\hline No & & Sequence $\mathbf{( 5 \rightarrow 3 )}$ \\
\hline 1 & Forward Primer & ACTGACCCCGGTGGCGGAGGAGACGTGC \\
\hline 2 & Reverse Primer & TGTTCCACCAGGGGCCCCAGGCGCTCGCGG \\
\hline
\end{tabular}

Table 3:- Distribution of ApoE Gene in TBI patients

\begin{tabular}{|c|c|c|c|}
\hline & Polymorphism & Distribution & Total \\
\hline \multirow{3}{*}{$\varepsilon 4$ Negative } & $\varepsilon 2 / \varepsilon 2$ & $000 / 172(00.0 \%)$ & \multirow{2}{*}{$161 / 172(93.6 \%)$} \\
\cline { 2 - 3 } & $\varepsilon 2 / \varepsilon 3$ & $025 / 172(14.5 \%)$ & \\
\cline { 2 - 3 } & $\varepsilon 3 / \varepsilon 3$ & $136 / 172(79.1 \%)$ & \\
\hline \multirow{2}{*}{$\varepsilon 4$ Positive } & $\varepsilon 2 / \varepsilon 4$ & $002 / 172(01.2 \%)$ & \multirow{2}{*}{$011 / 172(06.4 \%)$} \\
\cline { 2 - 3 } & $\varepsilon 3 / \varepsilon 4$ & $007 / 172(04.1 \%)$ & \\
\cline { 2 - 3 } & $\varepsilon 4 / \varepsilon 4$ & $002 / 172(01.2 \%)$ & \\
\hline
\end{tabular}

Table 4:- Age wise distribution of patients

\begin{tabular}{|c|c|c|}
\hline Age & Number of patient & Distribution \\
\hline$<21 \mathrm{yrs}$ & 24 & $24 / 172(13.9 \%)$ \\
\hline $21-40 \mathrm{yrs}$ & 86 & $86 / 172(50.0 \%)$ \\
\hline $41-60 \mathrm{yrs}$ & 49 & $49 / 172(28.5 \%)$ \\
\hline$>60 \mathrm{yrs}$ & 13 & $13 / 172(07.5 \%)$ \\
\hline
\end{tabular}

Table 5:- Age-wise distribution of mild and moderate TBI

\begin{tabular}{|c|c|c|c|c|c|c|}
\hline & & $<\mathbf{2 1}$ yrs & $\mathbf{2 1 - 4 0 ~ y r s}$ & $\mathbf{4 1 - 6 0}$ yrs & $\mathbf{> 6 0}$ yrs & Total \\
\hline \multirow{3}{*}{ APOE-\&4 Negative } & Mild HI & 09 & 31 & 18 & 05 & 63 \\
\cline { 2 - 7 } & Moderate HI & 08 & 28 & 20 & 03 & 59 \\
\cline { 2 - 7 } & total & 17 & 59 & 38 & 08 & 122 \\
\hline \multirow{3}{*}{ APOE- $\varepsilon 4$ Positive } & Mild HI & 00 & 04 & 00 & 01 & 05 \\
\cline { 2 - 7 } & Moderate HI & 00 & 03 & 02 & 01 & 06 \\
\cline { 2 - 7 } & total & 00 & 07 & 02 & 02 & 11 \\
\hline
\end{tabular}

Table 6:- Etiology of head injury.

\begin{tabular}{|c|c|c|}
\hline Cause of head injury & Number of patient & Distribution \\
\hline RTA & 126 & $126 / 172(73.3 \%)$ \\
\hline Fall & 32 & $032 / 172(18.6 \%)$ \\
\hline Other & 14 & $014 / 172(08.1 \%)$ \\
\hline
\end{tabular}

Table 7:- APO E4 and Glasgow Outcome Score (GOS)

\begin{tabular}{|c|c|c|c|}
\hline \multirow{2}{*}{} & Total number of patient & \multicolumn{2}{|c|}{ Glasgow outcome Score } \\
\cline { 3 - 4 } & & unfavorable(1-3) & favorable (4-5) \\
\hline ApoE- $\varepsilon 4$ Negative & 122 & 17 & 105 \\
\hline ApoE- $\varepsilon 4$ Positive & 11 & 2 & 9 \\
\hline
\end{tabular}




\section{Discussion:-}

S. S. K. M. Hospital, located in Kolkata, is the main government hospital of West Bengal, India. Most of the patients admitted with Head Injury at our hospital are from districts like South 24 Parganas, North 24 Parganas, Kolkata, West Midnapur, East Midnapur and Burdwan districts. None of the patients in the study group are from North Bengal districts, which are at considerable distance from Kolkata.

Here, we have studied the demography of Head Injury as well as the role of ApoE- 44 in the outcome of head injury. 172 patients were included in the study and complete data including ApoE genotyping and 6 months follow up data is available for 133 patients. We have analyzed distribution of TBI in various age groups, sex, and mode of injury; its clinical outcome in relation to severity of brain injury.

ApoE has three isoforms and six genotypes. Analysis showed that the frequency of Apo $\varepsilon 2$, $\varepsilon 3$, and $\varepsilon 4$ in our study is $6.8 \%, 88.3 \%$ and $4.9 \%$ respectively with only $8.3 \%$ of the population being ApoE- $\varepsilon 4$ positive. A study from northern part of India shows similar distribution of ApoE in Indian population $(4.3 \%, 88.6 \% \text {, and } 7.1 \%)^{29}$. The frequency of ApoE- $\varepsilon 4$ is lower in our population as compared to other parts of the world is much higher. Studies from European countries quote the ApoE- $\varepsilon 4$ positivity of $30-37 \%^{13,14,15,16}$, whereas Nathoo et. al. ${ }^{17}$ from South Africa found $40.9 \%$ of population to be ApoE- $\varepsilon 4$ positive. Chiang et. al. ${ }^{18}$ from China have lower frequency of ApoE- $\varepsilon 4(9.5 \%)$ than the European studies with only $19 \%$ of study population positive for ApoE- $\varepsilon 4$. Overall in all the studies frequency of $\varepsilon 3$ allele is found to be highest $(60-90 \%)^{19}$.

In our study, male: female head injury ratio is 3:1. Commonly affected age group is 21-40 years (50\%), followed by 41-60 years (30\%). Road traffic accident is the most common cause of head injury amongst the study population (70\%), of which almost two third are due to bike accident. A study from Bangalore city had similar findings with male to female ratio of 1:0.3 and most common age group affected being 20-39 years. In most of the Indian studies road traffic accident was the most common etiology of head injury ${ }^{20}$. Alcohol consumption has been found to be a major risk factor for occurrence of head injury in our study. $26 \%$ of the total patients were found to be under alcohol influence at the time of head injury. Drunken driving cases are $20 \%$ of total RTA. Only one out of 63 bike riders was wearing helmet at the time of RTA. This is in contrast to developed countries where fall from height comprises most of the head injury.

Patients initial GOS on admission doesn't seem to correlate with ApoE- $\varepsilon 4$ status which is comparable to all other studies. Glasgow Outcome Score of 1-3 is considered to be unfavorable outcome and a score of $4 \& 5$ is a favorable outcome. There is no significant difference on final outcome between the two groups. Also the difference between mean hospital stay in both the groups is not statistically significant. This is in contrast to most of the studies from European countries, United States and Middle East countries and a study from China ${ }^{13,18,21-26}$ where Apo-E4 is found to have negative effect on the outcome of head injury. But other studies especially one from South Africa and Australia failed to show the same result ${ }^{15,16,27}$. Pruthi et. al. ${ }^{19}$ from India studied outcome of presence of ApoE- $\varepsilon 4$ and mild to moderate head injury in South Indian population where they found no significant negative effect of ApoE- $\varepsilon 4$. None of the 12 patients with presence of ApoE- $\varepsilon 4$ had poor outcome ${ }^{28}$. In a detailed neuropsychological assessment of 90 adult patients with mild and moderate TBI at six-month follow-up, Chamelian et. al. ${ }^{30}$ from Canada had found no effect of Apo-E4 allele on the poor outcome. Overall, we find that there is a good outcome in mild and moderate head injury which is comparable to other studies (97\% for mild and $73 \%$ for moderate head injury) $^{13,14,18,21-27}$.

Although there are few studies apart from United Kingdom and United States, studies from South Africa, India, Australia and Canada are suggestive of no effect of presence of ApoE- $\varepsilon 4$ allele on outcome of Head Injury. It is known that diet, lifestyle, environmental conditions seem to have influence on ApoE- $\varepsilon 4$ expression. Lifetime cognitive activity interacts with the ApoE- $\varepsilon 4$ carrier status to modulate $A \beta$ pathology. Specifically, higher cognitive activity correlates with lower A $\beta$-plaque burden particularly in E4 carriers. The lipidation states of apolipoproteins and $A \beta$ peptides in the brain differ depending on ApoE genotype and cognitive diagnosis. Concentrations can be modulated by diet. These findings may provide insight into the mechanisms through which apolipoprotein $\varepsilon 4$ and unhealthy diets impart risk for poor outcome in TBI. Hence, the theoretical explanation for our findings could be high susceptibility of ApoE gene product to environmental influences and dietary differences or presence of modifier genes in this ethnic population. 


\section{Conclusion:-}

In our study, we have found that head injury is more common in males than females and the commonest age group being affected is $20-40$ years. Road traffic accidents are the most common cause of head injury. A significant number of cases are due to drunken driving as per other Indian studies. Also, exploitation of road traffic safety precautions seems to be common here. Overall outcome of mild and moderate head injury in our study is comparable to most of the other studies. Allelic frequency of ApoE- $\varepsilon 4$ in Indian population is comparatively less than that of Western population. This study also indicates that there is no significant difference between ApoE- $\varepsilon 4$ positive and negative groups, if unfavorable outcome of head injury is taken into account.

\section{Acknowledgement:-}

The research work was financially supported by the West Bengal State Department of Science and Technology (WBDST).

\section{References:-}

1. Kay, T., Harrington, D.E., Adams, R., Anderson, T., Berrol, S., Cicerone, K., Dahlberg, C., Gerber, D., Goka, R., Harley, P., Hilt, J., Horn, L., Lehmkuhl, D. and Malec, J. (1993) Definition of Mild Traumatic Brain Injury. Head Trauma Rehabil., 8, 86-87.

2. Englander, J., Hall, K., Stimpsons, T. and Chaffin, S. (1992) Mild Traumatic Injury in an Insured Population: Subjective Complaints and Return to Employment. Brain Injury, 6, 161-166.

3. Teasdale, G. and Jennett, B. (1974) Assessment of Coma and Impaired Consciousness: A Practical Scale. Lancet, 304, 81-84.

4. http://www.ncbi.nlm.nih.gov/gene/348; APOE apolipoprotein E [Homo sapiens (human)] Gene ID: 348, updated on 13-Mar-2016.

5. Singh, P.P., Singh, M. and Mastana, S.S. (2002) Genetic variation of apolipoproteins in North Indians. Hum. Biol., 74 (5), 673-82.

6. Chawla, A., Boisvert, W.A., Lee, C.H., Laffitte, B.A., Barak, Y., Joseph, S.B., Liao, D., Nagy, L., Edwards, P.A., Curtiss, L.K., Evans, R.M., Tontonoz, P. (2001) A PPAR gamma-LXR-ABCA1 pathway in macrophages is involved in cholesterol efflux and atherogenesis. Mol.Cell, 7(1), 161-71.

7. Singh, P.P., Singh, M. and Mastana, S.S. (2006) APOE distribution in world populations with new data from India and the UK. Annals of Human Biology, 33 (3), 279-308.

8. Eisenberg, D.T., Kuzawa, C.W. and Hayes, M.G. (2010) Worldwide allele frequencies of the human apoliprotein E (APOE) gene: climate, local adaptations and evolutionary history. American Journal of Physical Anthropology, 143 (1), 100-111.

9. Ghebranious, N., Ivacic, L., Mallum, J. and Dokken, C. (2005) Detection of ApoE E2, E3 and E4 alleles using MALDI-TOF mass spectrometry and the homogeneous mass-extend technology. Nucleic Acids Res., 33(17), e149.

10. Online 'Mendelian Inheritance in Man' (OMIM) APOE3 isoform, hyperlipoproteinemia, type III, autosomal recessive $-107741 \# 0015$.

11. Online 'Mendelian Inheritance in Man' (OMIM) APOE3 isoform, APOE, CYS112 and ARG158 107741\#0001.

12. Zuo, L., Van Dyck, C.H., Luo, X., Kranzler, H.R., Yang, B.Z. and Gelernter, J. (2006) Variation at APOE and STH loci and Alzheimer's disease. Beha. Brain Funct. 2, 13.

13. Teasdale, G.M,, Nicoll, J.A., Murray, G. and Fiddes, M. (1997) Association of Apolipoprotein E Polymorphism with Outcome after Head Injury. Lancet, 350, 1069-1071.

14. Liaquat, I., Dunn, L.T., Nicoll, J.A., Teasdale, G.M. and Norrie, J.D. (2002) Effect of Apolipoprotein E Genotype on hematoma Volume after Trauma. J Neurosurg., 96, 90-96.

15. Millar, K., Nicoll, J.A., Thornhill, S., Murray, G.D. and Teasdale, G.M. (2003) Long Term Neuropsychological Outcome after Head Injury: Relation to APOE Genotype. J Neurol Neurosurg Psychiatry, 74, 1047-1052.

16. Teasdale, G.M., Murray, G.D. and Nicoll, J.A. (2005) The Association between APOE $\varepsilon 4$, Age and Outcome after Head Injury: a Prospective Cohort Study. Brain, 128, 2556-2561.

17. Nathoo, N., Chetty, R., Van Dellen, J.R., Conolly, C. and Naidoo, R. (2003) Apolipoprotein E Polymorphism and Outcome after Closed Traumatic Brain Injury: Influence of Ethnic and Regional Differences. J Neurosurg., 98, 302-306.

18. Chiang, M.F., Chang, J.G. and Hu, C.J. (2003) Association between Apolipoprotein E Genotype and Outcome of Traumatic Brain Injury. Acta Neurochir., 145, 649-653 
19. Pruthi, N., Chandramouli, B.A., Kuttappa, T.B., Rao, S.L., Subbakrishna, D.K., Abraham, M.P., Mahadevan, A. and Shankar, S.K. (2010) Apolipoprotein E Polymorphism and Outcome after Mild to Moderate Traumatic Brain Injury: A Study of Patient Population in India. Neurol. India, 58(2), 264-269.

20. Gururaj, G. (2002) Epidemiology of Traumatic Brain Injuries: Indian Scenario. Neurol Res., 24(1), 24-28.

21. Jordan, B.D., Relkin, N.R., Ravdin, L.D., Jacobs, A.R., Bennett, A. and Gandy, S. (1997) Apolipoprotein E $\varepsilon 4$ Associated with Chronic Traumatic Brain Injury in Boxing. JAMA, 278, 136-140.

22. Friedman, G., Froom, P., Sazbon, L., Grinblatt, I., Shochina, M., Tsenter, J., Babaaey, S., Yehuda, B. and Groswasser, Z. (1999) Apolipoprotein E- $\varepsilon 4$ Genotype Predicts a Poor Outcome in Survivors of Traumatic Brain Injury. Neurology, 52, 244-248

23. Lichtman, S.W., Seliger, G., Tycko, B. and Marder, K. (2000) Apolipoprotein E and Functional Recovery from Brain Injury Following Postacute Rehabilitation. Neurology, 55, 1536-1539

24. Crawford, F.C., Vanderploeg, R.D., Freeman, M.J., Singh, S., Waisman, M., Michaels, L., Abdullah, L., Warden, D., Lipsky, R., Salazar, A. and Mullan, M.J. (2002) APOE Genotype Influences Acquisition and Recall Following Traumatic Brain Injury. Neurology, 58, 1115-1118.

25. Sundström, A., Marklund, P., Nilsson, L.G., Cruts, M., Adolfsson, R., Van Broeckhoven, C. and Nyberg, L. (2004) APOE Influences on Neuropsychological Function after Mild Head Injury: Within-Person Comparisons. Neurology, 62, 1963-1966.

26. Liberman, J.N., Stewart, W.F., Wesnes, K. and Troncoso, J. (2002) Apolipoprotein E 84 and Short-term Recovery from Predominantly Mild Brain Injury. Neurology, 58, 1038-1044.

27. Ponsford, J., Rudzki, D., Bailey, K. and Ng, K.T. (2007) Impact of Apolipoprotein Gene on Cognitive Impairment and Recovery after Traumatic Brain Injury. Neurology, 68, 619-620.

28. Gallek, M.J., Conley, Y.P., Sherwood, P.R., Horowitz, M.B., Kassam, A. and Alexander, S.A. (2009) APOE Genotype and Functional Outcome Following Aneurysmal Subarachnoid Hemorrhage. Biol Res Nurs. 10(3), 205-212.

29. Singh, P.P., Singh, M. and Mastana, S.S. (2006) APOE distribution in world populations with new data from India and the UK. Ann Hum Biol. 33(3), 279-308.

30. Chamelian, L., Reis, M. and Feinstein, A. (2004) Six-month recovery from mild to moderate Traumatic Brain Injury: the role of APOE-e4 allele. Brain, 127, 2621-2628. 